\title{
Practice and Cognition of Midway VSP in High Temperature and High Pressure Field of South China Sea
}

\author{
Aiqun Liu*, Peiyuan Zhu, Bing Liu, Yunpeng Wu, Bentian Ou \\ Zhanjiang Branch of China National Offshore Oil Corporation Ltd., Zhanjiang, China \\ Email: *liuaq@cnooc.com.cn
}

How to cite this paper: Liu, A.Q., Zhu, P.Y., Liu, B., Wu, Y.P. and Ou, B.T. (2018) Practice and Cognition of Midway VSP in High Temperature and High Pressure Field of South China Sea. Open Journal of Geology, 8, 489-498.

https://doi.org/10.4236/ojg.2018.85029

Received: April 17, 2018

Accepted: May 19, 2018

Published: May 22, 2018

Copyright (c) 2018 by authors and Scientific Research Publishing Inc. This work is licensed under the Creative Commons Attribution International License (CC BY 4.0).

http://creativecommons.org/licenses/by/4.0/

\begin{abstract}
Ying-Qiong Basin is a typical high-temperature and overpressure basin, which is the main battlefield of oil and gas exploration in South China Sea and has made great breakthroughs in recent years. During drilling process in high pressure, the relationship between the deep and the pressure is directly related to the drilling safety and costs. In order to improve prediction accuracy, the VSP operation is carried out through the midway, and three points have been obtained: 1) The VSP has a higher accuracy of the interface depth in certain depth range of the drill bit. 2) When the low-frequency trend prediction is accurate before the drill bit, interval velocity of the VSP inversion is consistent with the formation velocity. 3) The VSP pressure forecast is based on the inversion layer velocity and under-compaction pressure. If the velocity prediction is not accurate, the pressure forecast must be erroneous. If the pressure has other sources, the formation pressure is not accurate even if the inversion velocity is accurate. The application scope and exploration effect of midway VSP operation are summarized and applied to Ledong 10-1 block in Yinggehai basin, which realize the breakthrough in the field of high temperature overpressure and provide the basis for other similar exploration areas to do VSP operation.
\end{abstract}

\section{Keywords}

High Temperature and High Pressure Well, Midway VSP, Interval Velocity Inversion, Low Frequency Trend, Pressure Prediction

\section{Introduction}

Ying-Qiong Cenozoic sedimentary basin is rapidly subsiding basins are charac- 
terized by abnormal high temperature and high pressure. Abnormal high pressure is mainly due to the late rapid subsidence and under-compaction mudstone formed by rapid deposition, which relies on steady subsidence and weak tectonic activity to maintain [1] [2] [3] [4]. The formation pressure structure directly affects the design of the drilling well structure and operation safety. Because of low drilling density and high drilling cost, prediction accuracy of pre-drilling time-depth relationship as well as formation pressure structure is not very high, so it is necessary to update in time by use of drilling data during drilling process. Midway VSP is a more practical targeted technology in high temperature and high pressure field of South China Sea, which is frequently used and can be measured with high precision and without delaying drilling cycle during the intermittent drilling interval. We can achieve time-depth relationship prediction above the drill and velocity inversion and pressure prediction below drill bit within a certain range.

According to the midway VSP measurement and prediction, the deep relationship and wellbore structure will be adjusted to improve drilling safety and save drilling costs. Application scope and exploration effect of the midway VSP operation in high temperature and high pressure field in recent years are summarized in this paper, which can provide evidence for other similar exploration areas.

\section{The Basic Principle and Method of Midway VSP}

The midway VSP logging principle is the same as the conventional VSP logging, which is a seismic observation method stimulated at the ground (sea surface) and received in wells developed from seismic logging (Figure 1). Assuming that the distance from the wellbore of the midway VSP logging is L, the depth of the detector in the well is $\mathrm{D}$, the depth of the air gun source is D1, and the initial take-off time of the detector is $\mathrm{T}$, then the average of the overlying strata Velocity is, If the initial value is accurate, the average velocity calculation is also

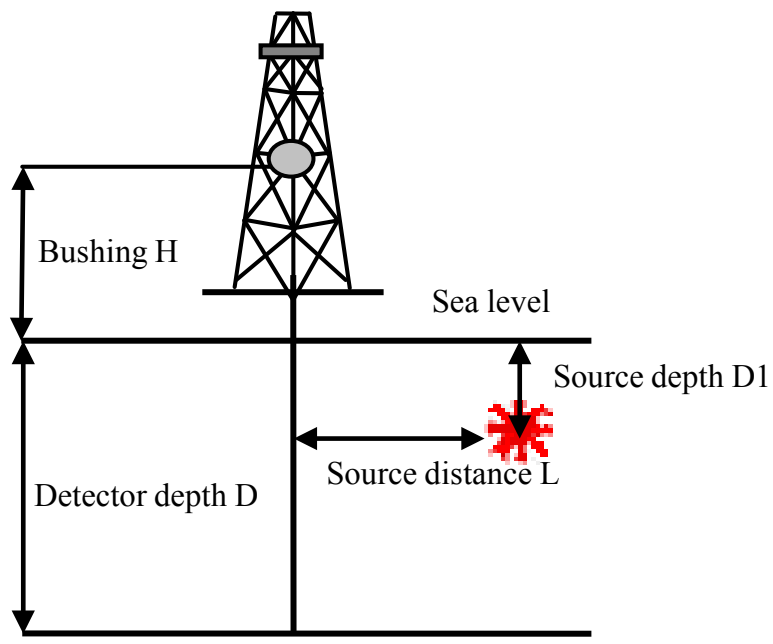

Figure 1. Midway VSP logging illustration at sea. 
accurate. However, the purpose of the midway VSP logging is not only for the average velocity, but usually in the casing under the deep critical position or close to the drill before the prediction of high pressure surface location above the measurement to predict the formation velocity and pressure structure below a certain depth of bit.

When detectors are arranged along the wellbore at different depths, midway VSP data is collected. Midway VSP data cannot only record the upstream wave (such as reflected wave) from below the observation point, but record the downstream wave (such as direct wave) from above the observation point. Observation in the well can greatly reduce or avoid the natural interference on the ground, which is conducive to wave records and recognition [5] [6] [7] [8] [9]. Midway VSP data processing can be divided into three steps: the first step is preprocessing, including data editing, editing, gain recovery etc. The second step is conventional processing, such as the first pick, static time shift and aligned, bandpass filter, amplitude processing, up and down wave field separation, deconvolution, superposition with depth, vertical stacking (corridor overlay) etc. The third step is special treatment, including offset VSP data processing, inclined well VSP, three component VSP data processing, Bayesian Seismic layer velocity inversion and pre-pressure prediction of the drill.

\section{Practice and Cognition of Midway VSP in High Temperature and High Pressure Field}

In recent years, great breakthroughs have taken placed in the high temperature and high pressure field of South China Sea with a number of large and medium gas fields and drilled high temperature and high pressure wells. In order to implement accurate time and depth relationship, forecast high pressure surface and optimize the drilling well structure design, advantages of midway VSP and the application scope are summed up as well as some technical limitations.

\subsection{The Midway VSP Can Accurately Predict Time and Depth Relationship within a Certain Depth before the Drill Bit}

With regard to the deepest point detector above the formation, midway VSP is used to calculate the average velocity and layer velocity directly for the depth of the detector and the first arrival time for the formation. The average velocity calculation formula has been already mentioned, the layer velocity is $v_{i}=\frac{z_{i}-z_{i-1}}{t_{i}-t_{i-1}}$ among which $z_{i}$ and $t_{i}$ are the depth and the first arrival time of the $i$ detector respectively, $z_{0}=0, t_{0}=0$. Since both $z_{i}$ and $t_{i}$ are known constants, in the case of $z_{i}-z_{i-1} \neq 0, v_{i}$ is a stable solution, so the average velocity above the drill bit and layer velocity calculation results are quite accurate. The accuracy of the prediction of the stratigraphic interface for a certain period of time before the drill bit depends on two points: one is time and depth relationship of the drill bit position, the other is the accuracy of the velocity prediction for a certain period of time before the drill bit. Regarding the issue above, firstly, 
as long as the accurate first pick up can achieve high-precision of time and depth relationship. Second point is whether there is a special lithology and depth range below drill bit, as shown in Table 1, $100 \mathrm{~ms}$ before drill bit, the error between predicted velocity and the true formation velocity are only $\pm 100 \mathrm{~m} / \mathrm{s}$, the interface depth prediction error will reach $\pm 15 \mathrm{~m}$. $500 \mathrm{~ms}$ before drill bit, if the error is less than $\pm 100 \mathrm{~m} / \mathrm{s}$, the error of the interface depth will also reach $\pm 50 \mathrm{~m}$, through the comparative analysis of errors, it is considered that the midway VSP depth prediction in a certain depth range before the drill bit is accurate.

\subsection{The Accuracy of the Midway VSP Layer Inversion Depend on Low Frequency Velocity}

The accuracy of the VSP layer velocity inversion is often determined by the low-frequency component, and the low-frequency component compensation is required due to the fact that the actual subsurface velocity cannot be obtained below the bit. The main purpose of the VSP velocity inversion is to predict the layer velocity of the strata below the depth of drill bit. Therefore, the low frequency constraint must not only for already drilling segment, but predict the "low tide" trend formation below the bit. Through many studies and applications, you can use the following methods to obtain the required low-frequency components.

\subsubsection{Seismic Velocity Spectrum Data Method}

The seismic velocity spectrum is the superposition velocity of the seismic scale obtained by velocity analysis in seismic data processing. For horizontal layered media, the stacking velocity is equal to the root mean square velocity [10] [11] [12] [13]. Therefore, the layer velocity can be further converted by the Dix formula by the root mean square velocity. The depth of conventional seismic exploration acquisition will be far greater than the mid-way VSP measurement depth, and the velocity spectrum can provide a relatively complete low-frequency trend that contains the drilled well and the segment to be drilled. But in the application, by contrast with the velocity curve with measured VSP, only with a better match can be applied to the final inversion.

\subsubsection{Acoustic Logging Filtering Method}

The extraction of the low frequency trend velocity is carried out by low-pass filtering of the logging acoustic velocity curve (Figure 2). Through the practical

Table 1. Interface prediction error table below Midway VSP drill bit.

\begin{tabular}{|c|c|c|c|c|}
\hline & $\begin{array}{c}\text { Formation } \\
\text { velocity } 3000 \mathrm{~m} / \mathrm{s}\end{array}$ & $\begin{array}{l}\text { Velocity error } \\
\pm 100 \mathrm{~m} / \mathrm{s}\end{array}$ & $\begin{array}{l}\text { Velocity error } \\
\pm 200 \mathrm{~m} / \mathrm{s}\end{array}$ & $\begin{array}{l}\text { Velocity error } \\
\pm 300 \mathrm{~m} / \mathrm{s}\end{array}$ \\
\hline $\begin{array}{l}\text { Before the drill bit } \\
\qquad 100 \mathrm{~ms}\end{array}$ & $150 \mathrm{~m}$ & $\pm 5 \mathrm{~m}$ & $\pm 10 \mathrm{~m}$ & $\pm 15 \mathrm{~m}$ \\
\hline $\begin{array}{l}\text { Before the drill bit } \\
\qquad 200 \mathrm{~ms}\end{array}$ & $300 \mathrm{~m}$ & $\pm 10 \mathrm{~m}$ & $\pm 20 \mathrm{~m}$ & $\pm 30 \mathrm{~m}$ \\
\hline $\begin{array}{l}\text { Before the drill bit } \\
\qquad 500 \mathrm{~ms}\end{array}$ & $750 \mathrm{~m}$ & $\pm 50 \mathrm{~m}$ & $\pm 100 \mathrm{~m}$ & $\pm 150 \mathrm{~m}$ \\
\hline
\end{tabular}




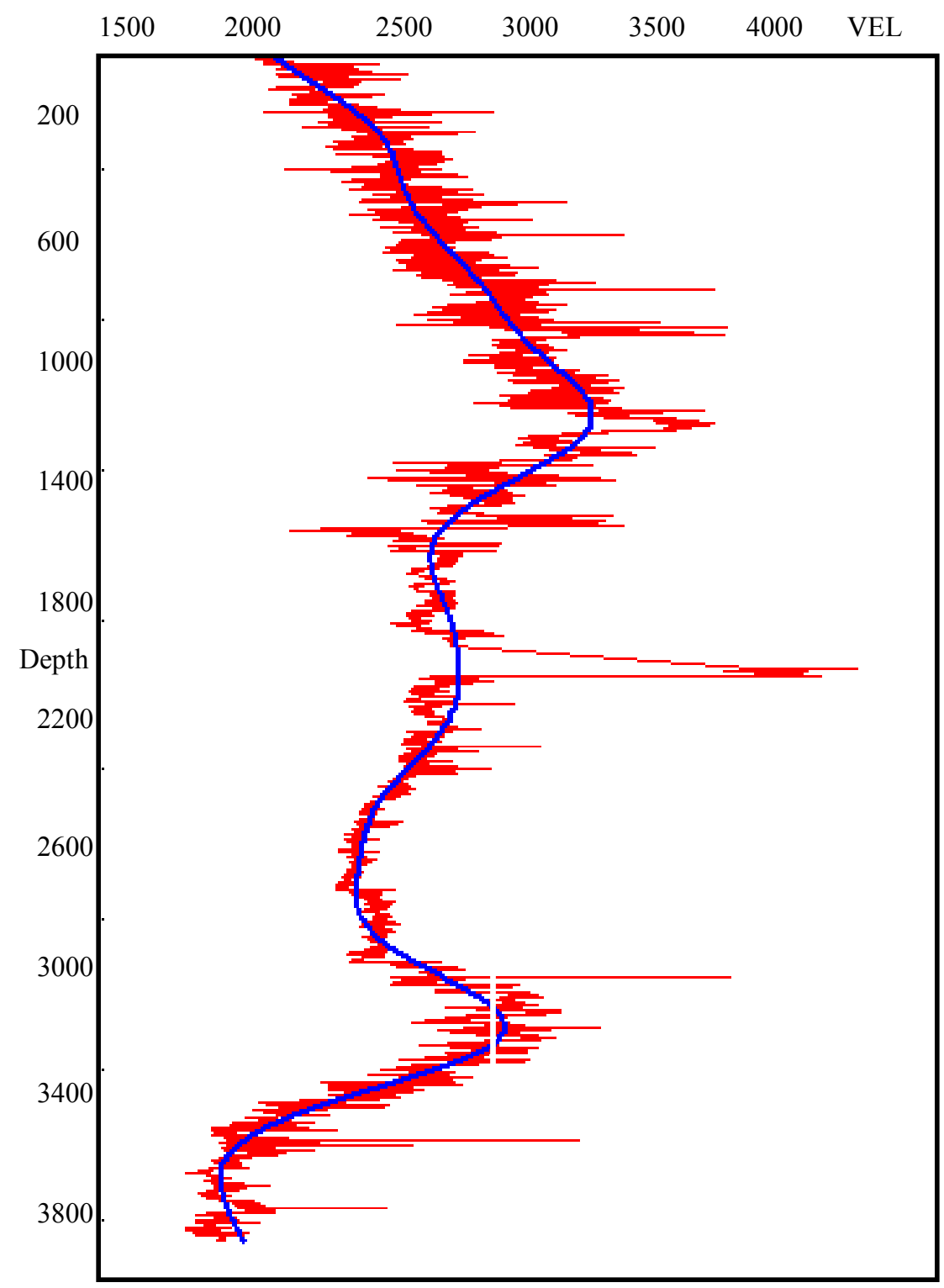

Figure 2. Acoustic velocity curve (red) and low frequency trend below $3 \mathrm{~Hz}$ (blue).

application, it is found that the low frequency filter $(3 \mathrm{HZ})$ is used to extract the low frequency component of the acoustic velocity. The extraction result has a good matching relationship with the measured VSP velocity. However, since the logging data range is also controlled by the drilling depth, the low frequency component obtained by this method can only provide the low frequency data of the measured section, it's better to be used in VSP velocity inversion with other methods.

\subsubsection{Primitive Extrapolation Method}

According to the measured VSP data, the corresponding time-depth relationship can be obtained. If the stratum is stable, time-depth relationship is relatively stable, through the initial relationship and curve fitting, time-depth relationship 
formula and time-depth trend are obtained, finally get the corresponding velocity trend.

Due to velocity reversal in high temperature and high pressure zone, a significant inflection point is found in the velocity trend of drilled wells. As shown in Figure 3(a), velocity trend of this well changes at $2000 \mathrm{~ms}$ (the velocity trend is from high to low) and the velocity below the bottom of the well by existing time-depth relationship shows a rapid decline (green line). Figure 3(b) shows that the upper and lower two sections of $2000 \mathrm{~ms}$ are fitted separately, and two low-frequency lines are obtained below $2000 \mathrm{~ms}$ (dark blue and light blue lines are corresponding to the upper and lower sections), below the bottom still shows obvious downward trend.

After comparison, it is found that the velocity trend extracted by the low-pass filter by acoustic logging and VSP measurement data is consistent with the measured velocity of the best. Layer velocity low frequency by velocity spectrum is basically able to reflect the trend of velocity, and contains the velocity information of the depth below the bottom of the well, which is the most complete low frequency trend. Time-depth relationship fitting extrapolation method has been affected by the measured velocity changes resulting in abnormal, and the trend of extrapolation of the credible range is small. To solve this problem, combined with the median extraction, velocity constraint is obtained by velocity median of the bottom and stable velocity change section. In the practical application, it's better to select the corresponding low-frequency acquisition method according to the existing data as well as low-frequency trend by a variety of methods. At present, it is ideal to use the method of time-depth

Time domain - time depth fitting and extrapolation

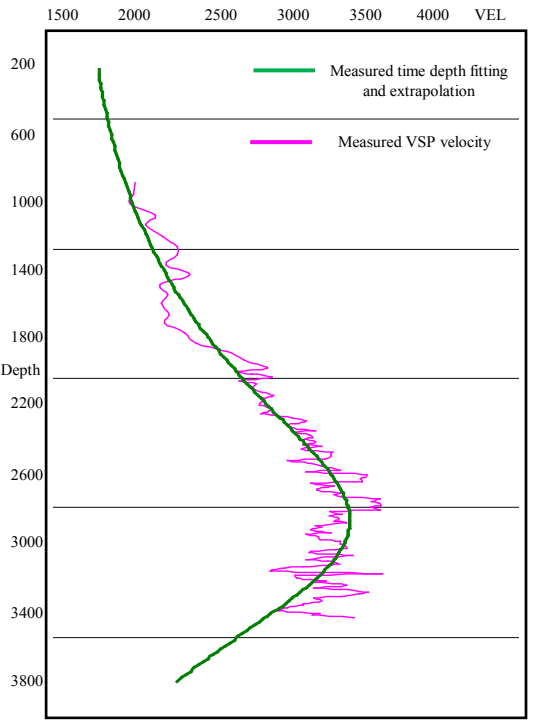

(a)

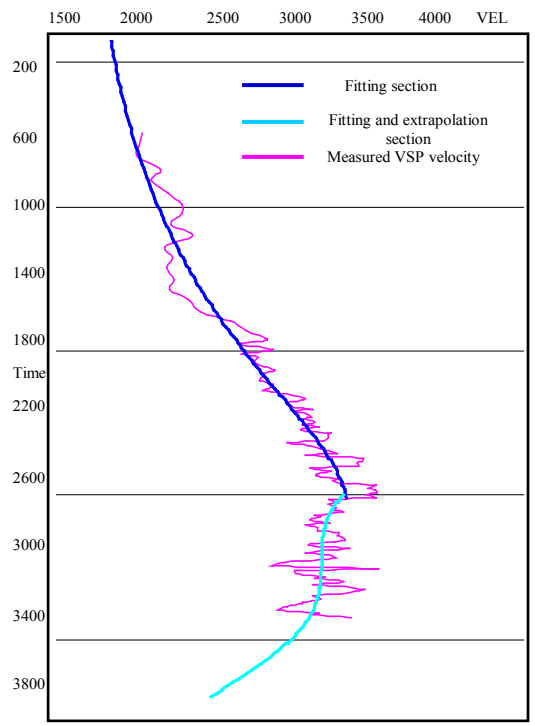

(b)

Figure 3. (a) The full-scale measured time-depth relationship fitting the extrapolation velocity curve; (b) Subparagraph measured time-depth relationship fitting the extrapolation velocity curve. 
relationship fitting, median extraction extrapolation and the application of extrapolation along the layer. When there is no special lithology before the drill bit, the trend of layer velocity by the midway VSP inversion is consistent with the measured velocity, and the accurate predicted velocity interface is got but some error in the layer velocity.

The midway VSP operation is carried out in the drill bit of YCA well (Figure 4), layer velocity inversion using the logging section of the time-depth relationship fitting extrapolation method to predict the low frequency trend, but owing to special lithology before the drill bit (normal compaction of mudstone and Ansan basalts), the real formation velocity is obviously higher than the predicted low frequency trend. Therefore, the VSP inversion velocity has lower accuracy, layer velocity and its trend are different from the measured velocity.

\subsection{The Accuracy of the Midway VSP Pore Pressure Prediction Depends on the Layer Velocity Inversion}

In order to determine the well structure as well as the mud system and improve drilling safety, midway VSP operation is needed in the high temperature and high pressure well to predict a certain depth of the bit through the inversion of the layer velocity. Layer velocity is the main parameter used for pre-drilling pressure prediction and pressure calculations while-drilling and post-drilling [14] [15]. In the normally compacted strata, the layer velocity increases with

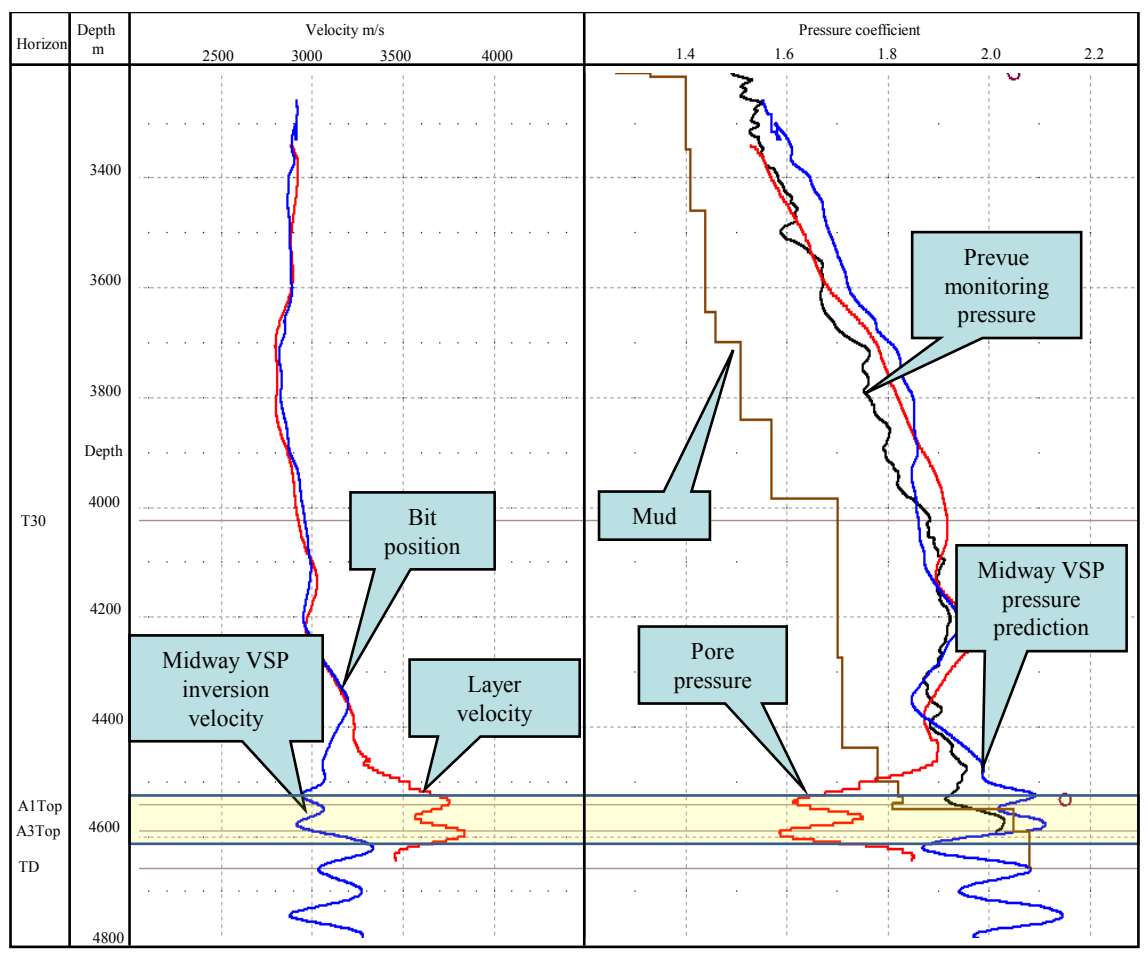

Pressure map of YC26-4-1

Figure 4. Midway VSP layer velocity inversion and pressure map in YCA well. 
depth, while in the anomalous high pressure formation (under-compaction mudstone) its value is smaller than the normal one, so it can judge and detect high pressure formations by abnormal changes in layer velocity. When there is special lithology below the drill bit, there is a large error in the low frequency trend and pressure prediction (Figure 4). When the low frequency trend selection is reasonable, it can realize the higher accuracy of the layer velocity prediction, and under the premise of the abnormal pressure of under-compaction with no pressure transmission, the prediction pressure interface and the trend are both accurate, which can achieve high precision pressure prediction (Table 2). However, when the anomalous pressure is due to the existence of pressure transfer (Figure 5), the layer velocity information cannot fully characterize layer pressure changes, formation pressure accuracy through VSP inversion is low, which can only reflect pressure trend of mudstone background but not the target layer pressure [16] [17] [18].

\section{Conclusion}

The midway VSP operation is becoming more and more important in the high temperature and high pressure field. Through the exploration research in recent years, the application scope and application effect of the midway VSP are summarized. When the large strata above the critical interface has no obvious signs or special geological purposes need to accurately implement the casing structure, the midway VSP below drill bit has higher accuracy. When there is no

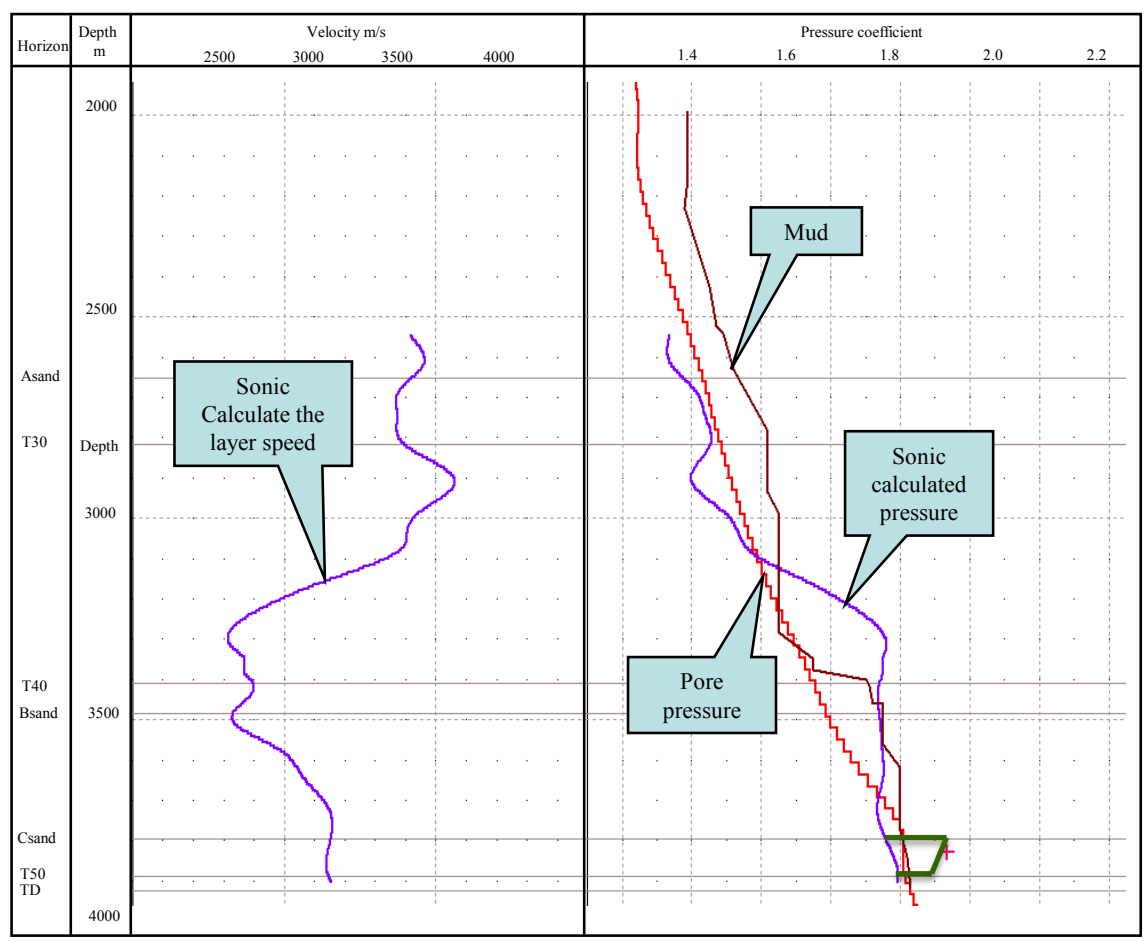

Pressure map of LS13-2W-1

Figure 5. Midway VSP inversion and completion pressure figure in LSB. 
Table 2. Midway VSP depth prediction and pressure coefficient error table of YCA and YCB.

\begin{tabular}{|c|c|c|c|c|c|c|c|c|}
\hline Borehole & Surface & $\begin{array}{c}\text { Depth } \\
\text { prediction }\end{array}$ & $\begin{array}{l}\text { Pore pressure } \\
\text { prediction }\end{array}$ & $\begin{array}{l}\text { Actual } \\
\text { depth }\end{array}$ & $\begin{array}{c}\text { Drilling } \\
\text { judgment or } \\
\text { calculated pressure }\end{array}$ & $\begin{array}{l}\text { Depth } \\
\text { error } \\
(\mathrm{m})\end{array}$ & $\begin{array}{c}\text { Pressure } \\
\text { error }\end{array}$ & $\begin{array}{l}\text { Relative } \\
\text { pressure } \\
\text { error (\%) }\end{array}$ \\
\hline YCA & $\mathrm{T} 30 \mathrm{~A}$ & 4534 & 2.09 & 4542 & 2.04 & -8.00 & 0.05 & 2.45 \\
\hline YCB & T62A & 5066 & 1.90 & 5068 & 1.84 & -2.00 & 0.06 & 3.26 \\
\hline
\end{tabular}

special lithology before the drill bit, layer velocity by density inversion is consistent with formation velocity with accurate velocity interface. When there is special lithology before the drill bit, the VSP inversion velocity is low, and the velocity and variation trend of the VSP inversion are different from the measured velocity. The pressure prediction is based on the layer velocity and under-compaction, if layer velocity prediction is not accurate, the pressure prediction must be erroneous. In the field of high temperature and overpressure in the South China Sea, owing to the high risk of drilling as well as the high precision of time-depth relationship and pressure prediction, it is necessary to strengthen the research and use of midway VSP, save the cost of drilling and improve the safety and effectiveness.

\section{National Fund Projects}

Thirteen Five Major Projects 2016ZX05024-005 Project. Enrichment Rules and Development Key Technology of High Temperature and High Pressure Natural Gas in Yinggehai-Qiongdongnan Basin (Phase 3).

\section{References}

[1] Wang, Z.F. and Hu, D.S. (1999) Prospecting for Giand Gas Fields in the Central Mud Diapir Structure Belt in Yinggehai Basin. Natural Gas Industry, 19, 106-109.

[2] Wang, Z.F. and Luo, X.R. (2004) Pressure Prediction Technology Research for Drilling Wells in HTHP Area of Ying-Qiong Basin. Petroleum Industry Press, Beijing.

[3] Liu, Q.W., He, J.X. and Chen, G.M. (2005) Gas Reservoir Characteristics of the Medium-Deep Strata in Yinggehai Basin. Natural Gas Industry, 22, 1-3.

[4] He, J.X., Xia, B., Liu, B.M., et al. (2005) Analysis of Conditions of Formation of Middle-and-Deep-Level Gas Accumulations in the Yinggehai Basin West of Hainan Island and Their Comparison with Those Shallow-Level Gas Accumulations. Geology Bulletion of China, 24, 9-15.

[5] Huang, B.J., Li, X.S., Yi, P., et al. (2005) Geochemical Behaviors and Reservoir History of Natural Gas in Ledong Gas Field in Yinggehai Basin. Oil \& Gas Geology, 26, 524-529.

[6] Hao, F., Dong, W.L., Zou, H.Y., et al. (2003) Overpressure Fluid and Rapid Accumulation of Natural Gas in Yinggehai Basin. Acta Petrolei Sinina, 24, 79-85.

[7] Liu, Z., Xu, X.M., Xie, Q.C., et al. (2006) Analysis on Late Origin of Overpressure in Bohai Bay Basin. Geoscience, 20, 260-267.

[8] Fan, H.H. and Zhang, C.J. (2005) New Methods for Calculation of Pore Pressure in 
Complex Geologic Environment. Petroleum Drlling Techniques, 33, 40-43.

[9] Ai, C., Feng, F.P. and Li, H.W. (2007) The Current Situation and Development Trend of Pore Pressure Prediction. Petroleum Geology and Engineering, 21, 71-73.

[10] Chen, X.G. (2005) Technology and Applications of 3D Formation Pressure Prediction. Petroleum Drilling Techniques, 33, 13-15.

[11] Zhu, Q.Z. (2001) Review of Abnormal Pressure Formation Mechanism. Natural Gas Exploration and Development, 24, 38-46.

[12] Sun, W.L. and Sun, K.F. (2007) Review of Pore-Pressure Prediction from Seismic Data. Progress in Exploration Geophysics, 30, 429-432.

[13] Zhang, S.L. and Zhao, M.H. (2002) Formation Pressure Prediction and Its Application in Reservoir Protection. Geological Science and Technology Information, 21, 43-47.

[14] Zhang, S.L. (2004) The Main Problems of Pre-Drilling Pressure Predition and the Resolution. Marine Geology Letters, 20, 36-40.

[15] Wang, Y.Q., Chen, Z.X., Yu, W.H., et al. (2005) Pore Pressure Prediction Research and Application in Qingtian Basin. Petrolem Drilling Techniques, 33, 29-31.

[16] Zhang, W.H., He, S. and Guo, Q.S. (2005) The Methods and Headway for Pressure Prediction. Process in Geophysics, 20, 814-817.

[17] Wei, M.A., Chen, C., Wang, Y.J., et al. (2007) New Approach for Pore Pressure Prediction. Oil \& Gas Geology, 28, 395-400.

[18] Ji, B.H. and Zong, X. (2007) Examination and Adjustment of Formation Pore Pressure through Fluid Logging. Petroleum Drilling Techniques, 35, 29-31. 